Anat. Inst. d. Mediz. Fak., Univ. Okayama (Vorstand. Prof. M. SEKI).

\title{
Über die Veränderung der Milchkügelchen durch histologische Fixierungsflüssigkeiten.
}

I. Durch die MÜLLERsche Flüssigkeit.

組織学固定液にての乳球の変化と就いて.

I. Müller 氏液飞て。

Shiro URABE 占 部 史朗.

(Eingegangen am 25. Januar 1957.)

Nach der Auffassung von MOHL (1951) u. a. findet sich auf der Oberfläche des Milchkügelchens eine dünne Schicht von Proteinstoffen, auf deren Innenseite aber eine ebenfalls dünne Lipoidenschicht, das Innere des Milchkügelchens besteht dagegen hauptsächlich aus Neutralfett. NISHINA (1953) ließ die Milch von Mensch und verschiedenen Tieren bei verschiedener Wärme stehen und färbte die Milchkügelchen nach Ablauf von Zeiten mit mittelstarkpolarem lipoidfärbendem Viktoriablau und nichtpolarem neutralfettfärbendem Sudan III und konstatierte, daß zuerst die Lipoidschicht demaskiert und dann das Neutralfett im Inneren des Milchkügelchens in ihre Komponente, Fettsäuren und Glycerin, gespalten und färbbar wurden. Ferner erfuhr man durch die Untersuchung von YASUDA (1955), daß durch Ultraschallwellen die Milchkügelchen mit Viktoriablau färbbar wurden.

Es ist in der Histologie wohl bekannt, daß die stark oxydierend wirkenden Bichromatanionen durch Lipoide in Gewebselementen reduziert und in niedrigere Oxydationsstufen, wie Chromoxyde und Chromhydroxyde, übergeführt werden und sich mit den Lipoiden verbinden. Die Lipoide werden dann in nichtwässerigen Flüssigkeiten, wie Alkohol, Benzol, Xylol usw. nicht löslich. Auf die Tatsache, daß bei einer solchen Chromierung freie Lipoide sich in den Gewebselementen vermehren, hat KARIYA (1955) aufmerksam gemacht. Er fixierte dabei Stückchen der Leber der Kuh in einer Kaliumbichromatlösung und färbte die Schnitte mit mittelstarkpolarem lipoidfärbendem Viktoriablau zur Darstellung von Lipoiden. Es hat sich nach der Untersuchung von SEKI (1956) herausgestellt, daß ebenfalls mittelstarkpolares Irisolechtviolett BBN, welches aber im Gegensatz zu schwach basischem Viktoriablau schwach sauer ist, auch die Lipoide gut färbt. In dem folgenden Experiment wurden als Versuchsmaterial Milchkügelchen der Kuh gewählt, die am einfachsten 
gebaut und deren chemische Komponente wohl bekannt sind. Die Milchkügelchen wurden mit der Bichromat enthaltenden MÜLLERschen Flüssigkeit fixiert, mit Irisolechtviolett BBN und Viktoriablau gefärbt und unter dem Mikroskop untersucht.

\section{Material und Methode.}

Man versetzte frische Kuhmilch mit 9facher Menge der MÜLLERschen Flüssigkeit ( $\mathrm{pH}$ 3.8), enthaltend 2.5\% iges Kaliumbichromat und 1\% iges Natriumsulfat. Zur Kontrolle wurde Milch mit 0.9\%iger Kochsalzlösung statt der MÜLLERschen Flüssigkeit versetzt. Die Mischungen wurden bei $37^{\circ} \mathrm{C} 1-30$ Tage lang stehen gelassen. Die Farblösungen wurden bereitet, indem man eine alkoholische 0.2\%ige Irisolechtviolett BBN- bzw. Viktoriablaulösung vor dem Gebrauch mit Wasser 20fach ver dünnte. Die Farblösungen enthielten also schließlich 5\%igen Alkohol und 0.01\%igen Farbstoff. $\mathrm{Zu}$ einem Tröpfchen der Färbungslösung auf dem Objektglas wurde ein Gemisch von Milch und der MÜLLERschen Lösung bzw. 0.9\%iger Kochsalzlösung in gleicher Menge versetzt. Man bedeckte die Mischung mit einem Deckglas und umrandete dies mit Vaselin. Die endgültige Konzentration des Alkohols in der Flüssigkeit unter dem Deckglas war zu 2.5\%, und die des Farbstoffes zu 0.005\%. Die Färbung der Milchkügelchen vollzog man mit Irisolechtviolett BBN für 12 Stunden, aber mit Viktoriablau für 1 Stunde, immer bei $37^{\circ} \mathrm{C}$. Sicherheitshalber wiederholte man die Untersuchung immer 5 Male.

\section{Ergebnisse der Untersuchung.}

Die frischen Milchkügelchen werden mit den beiden Farbstoffen nicht gefärbt. Die Färbungsstärke mit den beiden Farbstoffen der in der physiologischen Kochsalzlösung oder der MÜLLERschen Lösung verschiedene Zeiten lang aufbewahrten Milchkügelchen ist in der Tabelle auf der nächsten Seite zusammengestellt.

a) 1 Tag nach dem Zusetzen der M ̈̈LLERschen Flüssigkeit.

Färbung mit Irisolechtviolett BBN.

Die Milchkügelchen in der mit physiologischer Kochsalzlösung versetzten Milch färben sich nicht mit dem Farbstoff (Abb. 1).

Auch ihre Größe und Gestalt sind im Vergleich mit den frischen Milchkügelchen nicht verändert. Die mit der MÜLLERschen Flüssigkeit versetzten Milchkügelchen bleiben auch nicht färbbar. Indessen Vermindert sich ihre Lichtbrechung ein wenig. Man findet oft solche Milchkügelchen, die nicht von vollständig runder Form sind (Abb. 2).

Färbung mit Viktoriablau.

Die Milchkügelchen in der Kontrollmilchlösung sind mit dem Farb- 
Über die Veränderung der Milchkugelchen durch histologische usw.

Stärke der Färbbarkeit der Milchkügelchen nach der Verdünnung mit physiologischer Kochsalzlösung bzw. dem Zusatz der MÜLLERschen Flüssigkeit.

\begin{tabular}{c|c|c|c|c}
\hline $\begin{array}{c}\text { Ablauf } \\
\text { v. } \\
\text { Tagen }\end{array}$ & $\begin{array}{c}\text { Nach d. Verdünnung mit d. } \\
\text { physiol. Kochsalzlösung. }\end{array}$ & $\begin{array}{r}\text { Nach. d. Zusatz d. MüLLER- } \\
\text { schen Flüssigkeit. }\end{array}$ \\
\hline & $\begin{array}{c}\text { Irisolechtvio- } \\
\text { lett BBN }\end{array}$ & Viktoriablau & $\begin{array}{c}\text { Irisolechtvio- } \\
\text { lett BBN }\end{array}$ & Vikloriablau \\
\hline 1 & - & - & - & + \\
2 & + & + & + & + \\
3 & ++ & ++ & + & + \\
4 & +++ & ++++ & ++ & + \\
5 & ++++ & +++++ & ++ & + \\
6 & +++++ & +++++ & ++ & + \\
7 & +++++ & +++++ & ++ & + \\
15 & +++++ & +++++ & + & + \\
30 & +++++ & +++ & + & + \\
& & + & + & +
\end{tabular}

Abb. 1. 1 Tag nach der Verdünnung der Abb. 2. 1 Tag nach dem Zusetzen der Milch mit physiologischer Kochsalzlösung. MÜLLERschen Flüssigkeit. Färbung mit Färbung mit Irisolechtviolett BBN. Keine Irisolechtviolett BBN. Keine Färbung der Färbung der Milchkügelchen, auch keine Milchkügelchen. Sie vermindern die LichtVeränderungen ihrer Größe und Form. brechung und werden nicht vollständig $720 \times$. rund. $720 \times$.

stoff noch nicht färbbar (Abb. 3). Die Oberfläche der mit der MÜLLERscher Lösung versetzten Milchkügelchen wird aber stellenweise unregelmäßig schwach gefärbt, wie in Abb. 4 gezeigt ist. Auch in dieser Abbildung ist die Deformierung der Milchkügelchen ersichtlich.

b) 2 Tage nach dem Zusetzen der MÜLLERschen Flüssigkeit. Färbung mit Irisolechtviolett $B B N$.

Die Milchkügelchen in der Kontrollmilchlösung werden mit diesem 


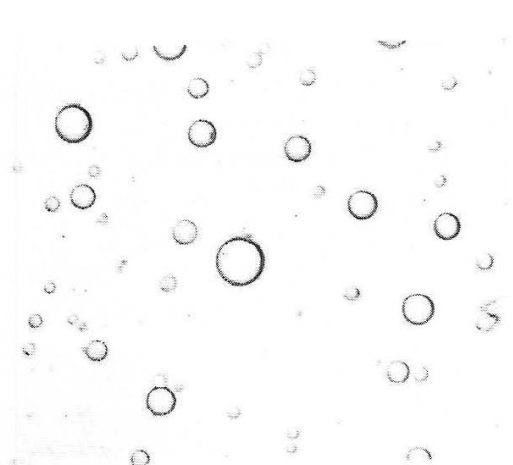

Abb. 3. 1 Tag nach der Verdünnung der Milch mit physiologischer Kochsalzlösung. Färbung mit Viktoriablau. Keine Färbung der Milchkügelchen. Ihre Form wie bei Abb. $1.720 \times$.

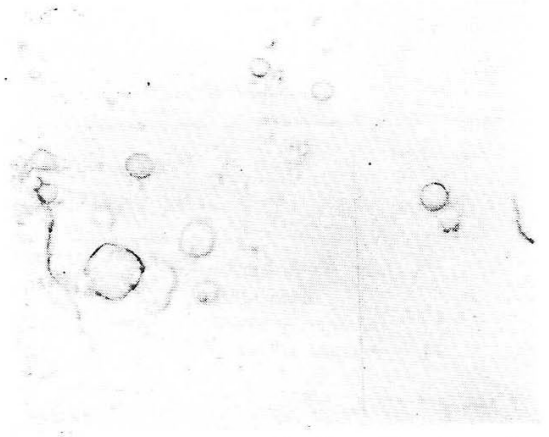

Abb. 4. 1 Tag nach dem Zusetzen der MÜLLERschen Flüssigkeit. Färbung mit Viktoriablau. Sehr schwache Färbung der Milchkügelchen. Thre Lichtbrechung und Form wie bei Abb. 2. $720 \times$.

Farbstoff schwach färbbar, ihre Größe und Form ändern sich aber kaum. Die der Wirkung der MÜLLERschen Flüssigkeit unterzogenen Milchkügelchen werden auch schwach färbbar. Die Veränderungen der Gestalt und Lichtbrechung sind beinahe die gleichen wie nach der ltägigen Wirkung der MÜLLERschen Flüssigkeit.

Färbung mit Viktoriablau.

Die in der mit Kochsalzlösung versetzten Milch vorhandenen Milchkügelchen können sich nun mit Viktoriablau schwach färben.

c) 3-5 Tage nach dem Zusetzen der M̈̈LLERschen Flussigkeit.

Fürbung mit Irisolechtviolett $B B N$.

1)ie in der Kontrollmilchlösung vorhandenen Milchkügelchen werden nach 3 Tagen noch etwas stärker färbbar als in früherer Zeit (Abb. 5). Die Färbbarkeit nimmt mit den Tagen immer mehr zu, während indessen fast keine Veränderungen der Größe und Gestalt der Milchkügelchen zutage treten. Die von der MÜLLERschen Flüssigkeit angegriffenen Milchkügel-

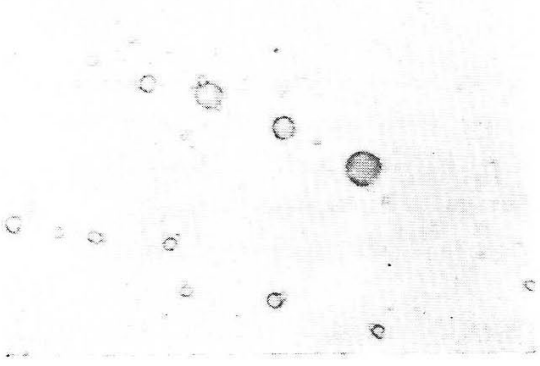

Abb. 5. 3 Tage nach der Verdünnung der Milch mit physiologischer Kochsalzlösung. Färbung mit Irisolechtviolett BBN. Mäßig starke Färbung der Milchkügelchen. Keine Veränderung der Größc und Form der Milchkügelchen. 
chen vermehren auch die Färbbarkeit nach und nach und werden zugleich unregelmäßig gestaltet. Sie ballen sich zum Teil zusammen (vgl. die mit Viktoriablau gefärbten Milchkügelchen in Abb. 6).

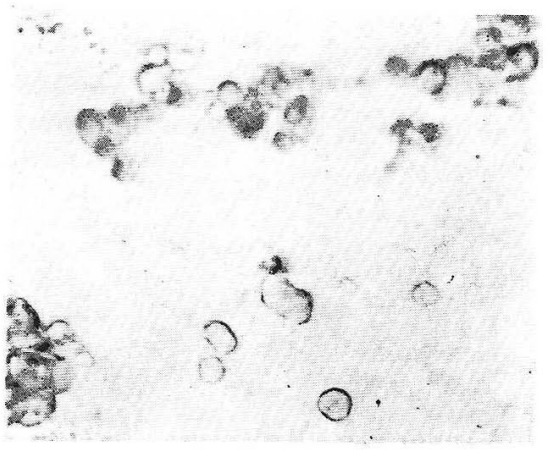

Abb. 6. 3 Tage nach dem Zusetzen der MÜLLAERschen Flüssigkeit. Färbung mit Viktoriablau. Die schwach gefärbten Milchkügelchen sind unregelmäßig gestaltet und ballen sich zum Teil zusammen.

\section{Färbung mit Viktoriablau.}

In der Kontrollmilchlösung nimmt auch die Färbbarkeit der Milchkügelchen mit diesem Farbstoff bedeutend zu. Die in der MÜLLERschen Flüssigkeit vorhandenen Milchkügelchen werden aber nur in geringerem Maße stärker färbbar. Die Deformierung und Zusammenballung der Michkügelchen treten auf, wie in Abb. 6 geziegt ist.

d) 6 Tage nach dem Zusetzen der MÜLLERschen Flüssigkeit.

Färbung mit Irisolechtviolett BBN.

Die in der mit physiologischer Kochsalzlösung verdünnten Milch gewesenen Milchkügelchen werden mit diesem Farbstoff stark violett gefärbt (Abb. 7), die Größe und Form bleiben indes fast nicht verändert. Die von

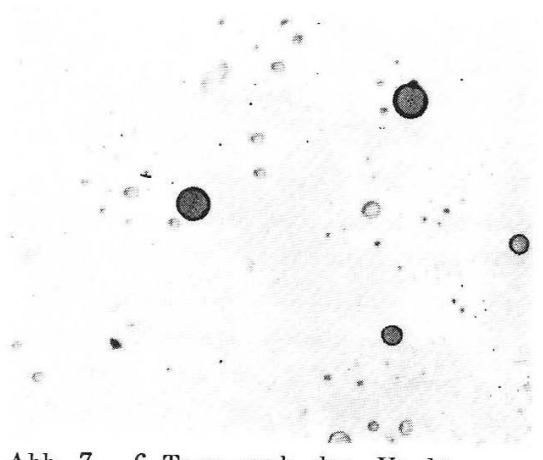

Abb. 7. 6 Tage nach der Verdünnung mit physiologischer Kochsalzlösung. Färbung mit Irisolechtviolett BBN. Starke Färbung der Milchkügelchen, aber keine Veränderungen ihrer Größe und Form.

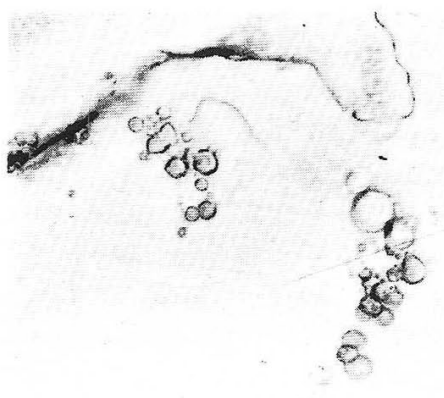

Abb. 8. 6 Tage nach dem Zusetzen der MÜLLERschen Flüssigkeit. Färbung mit Irisolechtviolett BBN. Die mäßig stark gefärbten Milchkügelchen sind etwas verkleinert, deformieren sich und ballen sich zusammen. 
der MÜLLERschen Flüssigkeit angegriffenen Milchkügelchen sind jedoch bei weitem schwächer zu färben (vgl. Abb. 8 mit 7). Die deformierten Milchkügelchen ballen sich zusammen.

Färbung mit Viktoriablau.

Die Milchkügelchen in der Kontrollmilchlösung färben sich mit diesem Farbstoff stark blau (Abb. 9). Die in der MÜLLERschen Flüssigkeit vorhandenen Milchkügelchen werden aber beträchtlich schwächer gefärbt als die in der Kontrollmilchlösung (Abb. 10).

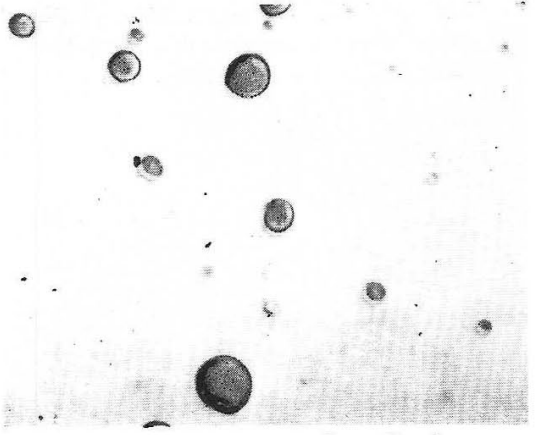

Abb. 9. 6 Tage nach der Verdünnung der Milch mit physiologischer Kochsalzlösung. Färbung mit Viktoriablau. Starke Färbung der Milchkügelchen. Ihre Größe und Form wie bei Abb. 7.

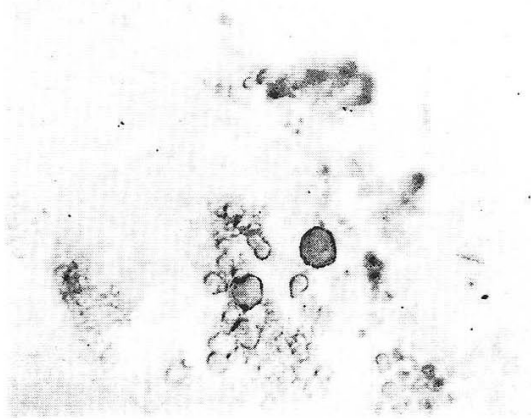

Abb. 10. 6 Tage nach dem Zusetzen der MÜLLERschen Flüssigkeit. Färbung mit Viktoriablau. Mäßig starke Färbung der Milchkügelchen. Ihre Form wie bei Abb. 8.

e) 7-30 Tage nach dem Zusetzen der MÜLLERschen Flüssigkeit.

Die Befunde sind im großen und ganzen die gleichen wie oben.

\section{Auswertung der Ergebnisse.}

Die Milchkügelchen in der mit physiologischer Kochsalzlösung verdünnten Milch werden immer noch der Wirkung der nativen Lipase in der Milch ausgesetzt. Nach Ablauf einer langen Zeit wird nalurgemäß das Neutralfett der Milchkügelchen in Glycerin und Fettsäuren gespalten, von denen das in Wasser lösliche Glycerin sich wahrscheinlich leicht nach außen löst, die Fettsäuren aber zum größten Teil in den Milchkügelchen zurückbleiben. Die letzteren müssen mit lipoidfärbendem Irisolechtviolett BBN und Viktoriablau gefärbt werden. Wenn die Milch aber mit der MÜLLERschen Lösung versetzt ist, wird zwar die Lipase durch starke kaustische Wirkung von Bichromat-Sulfatgemisch vernichtet, aber die wahrscheinlich an der Oberflächliche der Milchkügelchen vorhandene Proteinschicht wird dadurch leicht zerstört, so daß die inneren Lipoidensubstanzen sich demaskieren. Später muß aber auch das Neutralfett im Inneren der Milchkügelchen zum Teil durch das stark oxydierende Bichro- 
mat-Sulfatgemisch in Glycerin und Fettsäuren gespalten und mit den lipoidfärbenden Farbstoffen färbbar gemacht werden.

Mit dem Fortschreiten der Spaltung von Lipoiden und Neutralfett in der Oberfläche der Milchkügelchen wird eine schroffe Differenz der Lichtbrechung, zwischen der Oberfläche der Milchkügelchen und dem äußeren wässerigen Medium ermäßigt, wird also die Schärfe der Kontur der Milchkügelchen vermindert. Gleichzeitig vermindert freilich die Oberfläche der Milchkügelchen ihre hydrophobe Eigenschaft und wird mehr hydrophil. Diese Veränderung scheint in der Milchkügelchenoberfläche ungleichmäßig zu erfolgen, da die Milchkügelchen sich deformieren. Sie ballen sich schlieBlich zusammen.

\section{Zusammenfassung.}

1. Die frischen Milchkügelchen in der Kuhmilch sind vollständig rund, stark lichtbrechend und unter dem Lichtmikroskop sehr scharf umrissen. Sie färben sich mit keinen lipoidfärbenden mittelstarkpolaren Farbstoffen. Versetzt man die Milch mit einer großen Menge der MU̇LLERschen Flüssigkeit, die Kaliumbichromat und 'Natriumsulfat enthält, und läßt das Gemisch bei $37^{\circ} \mathrm{C}$ stehen, so nehmen die Milchkügelchen allmählich an der Stärke der Lichtbrechung ab, werden nicht rund und sowohl mit lipoidfärbendem, schwach saurem Irisolechtviolett BBN als auch mit ebenfalls lipoidfärbendem, schwach basischem Viktoriablau färbbar. Die Milchkügelchen ballen sich schließlich zusammen.

2. Die Milchkügelchen in der mit 0.9\%iger physiologischen Kochsalzlösung verdünnten Milch werden etwas später mit den obigen Farbstoffen anfärbbar als beim Zusetzen der MÜLLERschen Flüssigkeit. Nach Ablauf längerer Zeit werden sie jedoch beträchtlich stark färbbar. Sie bleiben aber immer vollständig rund und ballten sich nicht zusammen.

3. Die in der mit Kochsalzlösung verdünnten Milch vorhandenen Milchkügelchen werden naturgemäß von nativer Lipase angegriffen, so daß ihr Neutralfett allmählich in Glycerin und Fettsäuren gespaltet wird. Diese Produkte färben sich mit den beiden Farbstoffen. Die MÜLLERsche Flüssigkeit vernichtet dagegen die Lipasenwirkung, demaskiert aber durch ihre starke oxydierende Wirkung Lipoide an der Oberfläche der Milchkügelchen und zerlegt ferner Neutralfett bis zu einem gewissen Grad in seinen Komponenten. Die Frage, wie die MÜLLERsche Flüssigkeit dabei nicht gleichmäßig Veränderungen der Oberfläche der Milchkügelchen bewirkt und diese derformiert, muß in dieser Untersuchung dahingestellt bleiben.

\section{内 容 自 抄.}

\section{牛乳飞重クロム酸カリと硫酸ソーダを有する Müller 氏液を 9 倍量混じ，}


対照では牛乳を $0.9 \%$ 生理的食塩溶液で 9 倍に薄め, $37^{\circ} \mathrm{C}$ に 1 - 30 日間 置き, 類脂質を染める弱酸性の Irisolechtviolett BBN と弱塩基性のViktoriablau で乳球を染めることを試みた。

新鮮な牛乳の乳球は完全に球形で両染料に染まらないが，Müller 氏液 が加えられると, 乳球は変形し, 両染料でかなりよく染まり得るようにな り, 数日後には互いに凝集する。食塩溶液で薄められた牛乳の乳球は Müller 氏液が加えられた場合よりも両染料に染るようになるのが遅いけ れども，日の経過と共に雨染料に甚だ強く染り得るに至る。しかし乳球は 常飞球形飞止まり，互い凝集しない。

食塩溶液で薄められた乳汁内の乳球の中性脂肪は勿論そこに自然飞存在 する脂肪分解酵素の作用飞より，グリ七リンと脂肪酸に分解せられて，両 染料によく染まるようになるものであろ5。.Müller 氏液が牛乳飞加わる ときは，そこにある脂肪分解䤏素が速かに害され，その脂肪分解作用が止 むに違いないが，乳球表面の蛋白質の破壞とより類脂質が脱仮面せられ， 且つ内部の中性脂肪が一定度その成分飞分解せられるから, やはり雨染料 に染まり得るようになるのであるう。乳球が変形するのは Müller 氏液が 不均等にその表面を変化するからであることに疑いないが，その不均等の 理由はまだ明かにされない.

\section{Literatur.}

Kariya, T. : Vergleichende Untersuchung über die demaskierende Wirkung der Fixierungsflüssigkeiten auf die Lipoidsubstanz der Leberzellen. Arch. hist. jap. 8 (1955). - Mohr, W. H.: Heutige Milchwissenschaft und Versorgung der Bevölkerung mit einwandfreier Kindermilch. Mschr. Kinderhk. 99 (1951). Nishina, T.: Mikroskopische Untersuchung der Veränderung der Milch des Menschen und Tiere beim längeren Stehen. Arch. hist. jap. 5 (1953). - Seki, M.: Methodik zur Färbung der freien dipolhaltigen Lipoide in ihren natürlichen'Zuständen. Arch. hist. jap. 10 (1955). - Yasuda, H.: Färbung der durch Ultraschallwirkung zersetzten Milchkügelchen mit lipoidfärbendem Viktoriablau. Arch. hist. jap. 9 (1955). 